Journal of Case Reports 2017;7(2):143-145

\title{
Ectopia Cordis: A Case Report and Review of Literature
}

\author{
Habou Oumarou ${ }^{1}$, Magagi Ibrahim Amadou ${ }^{2}$, Adamou Harissou ${ }^{2}$, Adakal Ousseini² \\ Departments of ${ }^{1}$ Pediatric Surgery and ${ }^{2}$ General Surgery, National Hospital of Zinder, University of Zinder, BP: 155, Zinder (Niger).
}

\begin{abstract}
Corresponding Author:
Dr. Habou Oumarou

Email: bhomar70@yahoo.fr

This is an Open Access article distributed under the terms of the Creative Commons Attribution License (creativecommons.org/ licenses/by/3.0).
\end{abstract}

Received Accepted

Published

December 26, 2016

March 21, 2017

April 15, 2017

\begin{abstract}
Background: Ectopia cordis is a rare congenital anomaly characterized by partial or complete displacement of the heart outside the thoracic cavity. Here, we report a case of two-day-old black neonate born with an ectopia cordis associated with an omphalocele. Case Report: A full-term, barely responsive, black newborn presented at the pediatric surgery department with a heart totally outside the thoracic cavity without pericardium protection and an omphalocele. The baby was transferred immediately to the intensive care unit but died a few hours later before any surgical treatment. Conclusion: Ectopia cordis is an uncommon congenital anomaly. Its management represents a challenge even in developed country, and its prognosis is poor despite advances in neonatal cardiac surgery.
\end{abstract}

Keywords: Ectopia Cordis, Infant, Pentology of Cantrell, Pericardium, Thoracic Cavity.

\section{Introduction}

Ectopia cordis is a rare congenital anomaly defined as partial or complete displacement of the heart outside the thoracic cavity [1-5]. It is a ventral body wall defect concerning approximately 5.5 to 7.9 cases per million live births [1-3,6,7]. Ectopia cordis can be isolated or associated with other abnormalities [1-7]. Its etiology remains unknown and its prognosis is poor, mostly in developing country [2-4,6]. Here, we report the case of an ectopia cordis in a two-day-old neonate.

\section{Case Report}

A full-term, two-day-old, black male neonate, delivered vaginally, was referred to our department for malformative syndrome. He was the first child of a non-consanguineous couple. There was no family history of congenital abnormalities. The 24 year old mother was gravida 1, para 1, and had no history of medication with uneventful pregnancy course. Pregnancy was poorly monitored with only two prenatal consultations. No folic acid prophylaxis and no obstetric ultrasound were performed. The child was born in a low health care center located far from a tertiary hospital. At birth, Apgar's score was 8 and then 10, respectively at one and five minutes. He weighed 3300 grams with a length of 51 centimeters. He had a thoraco-abdominal defect with a heart outside the rib cage. In front of this malformative syndrome, the newborn was sent to the pediatric surgery department for better management.

The physical examination found a barely responsive newborn with an absence of the sternum and an externalized heart totally outside of the chest, without pericardium protection and omphalocele type 2 according to the classification of Aitken [Fig.1]. No other visible defects were found. There was an amniotic band at the first two phalanges of $3^{\text {rd }}$ and $4^{\text {th }}$ fingers of left hand (black arrows). The remainder of the physical examination was unremarkable.

The pulmonary radiograph showed a sternal cleft with an externalized heart. Cardiac ultrasound could not be performed. The abdomino-pelvic and trans-fontanellar ultrasounds were normal. Current 
laboratory tests were normal. The diagnosis of ectopia cordis was made and the newborn was transferred to the intensive care unit where he was put in a sterile blanket with coverage of exposed heart with saline-soaked gauze. Resuscitation measures were realized. He died a few hours later before surgery. The autopsy was not performed due to lack of parental consent.

\section{Discussion}

Ectopia cordis is an uncommon congenital heart disease with a scarce prevalence especially in Africa [2,3,5-7]. Ectopia cordis can be complete as in our case, with the heart entirely outside the thoracic cavity with or without a pericardial covering or partial, in which the heart is covered by skin at birth $[1,8]$. The first known case of ectopia cordis was reported by Stensen in 1671 [1,5]. It was first described by Haller in 1706 and classified into 5 types by Weese in 1818 and Todd in 1836 [1]. Depending upon the location of the heart and underlying defect, the following classification was proposed: cervical $(3 \%)$, cervicothoracic $(<1 \%)$, thoracic $(60 \%)$, thoraco-abdominal $(7 \%)$ and abdominal (30\%). The most common reported types are thoracic and thoraco-abdominal $[1,4,5,8]$.

The thoraco-abdominal type is frequently associated with another rare congenital anomaly known as pentalogy of Cantrell [1]. An abnormal closure of the ventral body wall by the lateral body wall folds and an arrest of cardiac descent during this stage $\left(3^{\text {th }}-4^{\text {th }}\right.$ embryonic week) may results in disorders varying from isolated ectopia cordis to complete ventral evisceration $[2,3,5,7,9]$. Although genesis of ectopia cordis has not been fully explained, several theories are suggested: early rupture of the chorion and/or the yolk sac or amniotic band syndrome $[1,3,5]$.

Most patients with ectopia cordis have associated intra-cardiac defect such as ventricular septal defect, atrial septal defect, tetralogy of Fallot, and diverticulum of the ventricle [1,7]. Ectopia cordis is reported to be often associated with

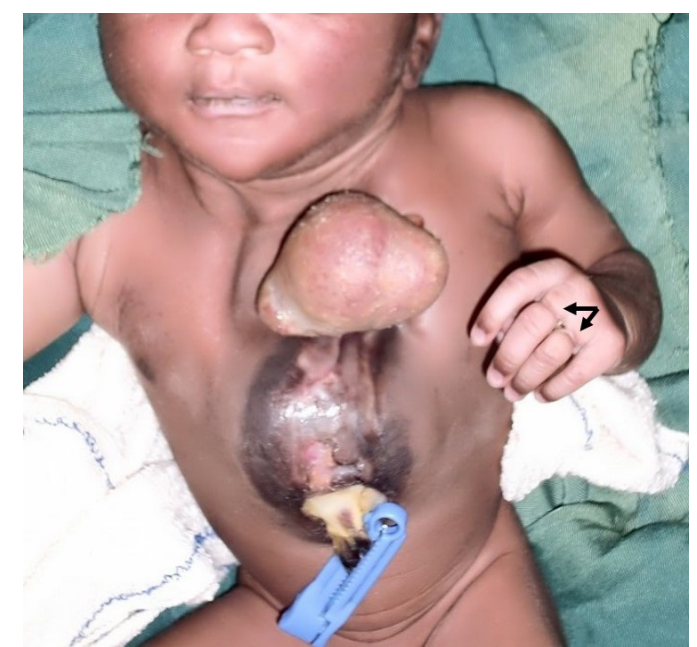

Fig.1: Neonate with an externally visible heart; omphalocele inferior to ectopic heart and amniotic band on the $3^{\text {rd }}$ and $4^{\text {th }}$ fingers of left hand (black arrows).

hydrocephalus, cleft lift and palate, hypoplastic lung disease, skeletal dysplasia, diaphragmatic hernia, abdominal wall defect, cranial and facial malformations, neural tube defect, genitourinary malformation, gastrointestinal defect and chromosomal abnormalities (trisomy 18, Turner syndrom) [1,3-7].

Ectopia cordis can be diagnosed by prenatal ultrasonography as early as in 9-12 weeks of pregnancy $[3,5,7]$. Ultrasound visualize the heart outside the thoracic cavity $[3,5,7,10,11]$. The use of three-dimensional ultrasound and its combination with Doppler allows more accurate early diagnosis [8,11]. Magnetic resonance imagery (MRI) and fetal echocardiography can be used to monitor development of the condition throughout pregnancy [1]. Postnatal echocardiography must be performed to diagnose associated cardiac anomalies [5].

Neonates with this life-threatening anomaly require intensive care from birth. The immediate treatment consists in resuscitation and coverage of the exposed heart and viscera with salinesoaked gauze or adherent plastic drapes to prevent desiccation $[3,12]$. Surgery in complete ectopia cordis remains a challenge worldwide, despite the advances in neonatal cardiac surgery $[3,5]$. 
Small thoracic cavity and positioning of great vessels attempting to close the chest wall leads to hemodynamic embarrassment [3]. Staged repair is usually necessary. Five surgical steps are identified after complete survey for additional congenital defects: closure of the chest wall defect, closure of the sternal defect, repair of the associated omphalocele, reduction of the heart into the chest cavity and repair of the intra-cardiac defect $[1,3,4]$. Some authors proposed a new approach to wound management and integrated palliative care that enabled community-based care for the management of complete ectopia cordis [12].

The prognosis depends on the degree of the intra-cardiac and associated malformations, the variety of ectopia cordis and the technical equipment for neonatal resuscitation $[3,5,7]$. Cardiac rupture, tamponade, sudden death, endocarditis, peripheral embolism, heart failure and arrhythmias have all been identified as complications associated with ectopia cordis [1]. The neonate is also exposed to risk of direct trauma and recurrent chest infections [1]. The thoracic variety have the worst prognosis with $<5 \%$ surviving beyond the first month of life; in this variety the average survival time after birth is 36 hours [3,7]. Complete ectopia cordis, in which the heart is covered only by a serous membrane, is a lethal form of the disease $[1,5,7]$. All unoperated neonate died within the first hours of birth $[3,7]$. There are few reports of long-term survivors, mostly with partial ectopia cordis, thoracoabdominal type and few or none complications $[1,3]$. Considering the poor prognosis, some authors suggest the termination of the pregnancy if ultrasound diagnosis is made before viability $[1,7]$. In poor and under-equipped countries like Niger, resuscitation and neonatal cardiac surgery are almost impossible, so the appearance of this malformation is often synonymous of neonatal death in the days following childbirth [4,5].

\section{Conclusion}

Ectopia cordis is a rare congenital malformation. Its management requires prompt medical care and surgical intervention taking co-morbidities into account. The prognosis is poor and related to associated anomalies and suitable timing in the repairs.

Contributors: HO, MIA: drafted the initial manuscript and literature review; $\mathrm{AH}$ : reviewed the literature and helped in manuscript preparation; AO: edited the manuscript and reviewed the literature. $\mathrm{HO}$ will act as guarantor. All authors approved the final version of the manuscript.

Funding: None; Competing interests: None stated.

\section{References}

1. Gabriel A, Donnelly J, Kuc A, Good A, Doros G, Matusz P, et al. Ectopia Cordis: A Rare Congenital Anomaly. Clin Anat. 2014;27:1193-1199.

2. Sadler TW. The embryologic origin of ventral body wall defects. Semin. Pediatr. Surg. 2010;19(3):209-214.

3. Shad J, Budhwani K, Biswas R. Thoracic ectopia cordis. BMJ Case Rep. 2012; doi:10.1136/bcr.11.2011.5241.

4. Chishugi JB, Franke TJ. Thoraco-abdominal ectopia cordis in Southwest Cameroon. Pan Afr Med J. 2014;18:124.

5. Ucima N, Tuka DD, Kimbongila MM, Lumbala PK, Biselele T,Tady BM, et al. Rare Occurrence of Ectopia Cordis in a Congolese Neonate. Pediatr Neonatol. 2015;56:132-133.

6. Amitabh P, Sharan R, Talapatra A. Ectopia cordis. J Clin Neonatol. 2012;1(3):166-167.

7. Taksande AM, Vilhekar KY. A case report of ectopia cordis and omphalocele. Indian $\mathrm{J}$ Hum Genet. 2013;19:491-493.

8. Puvabanditsin S, Di Stefano V, Garrow E, Wong R, Eng J, Balbin J. Ectopia cordis. Hong Kong Med J. 2013;19:447-450.

9. Sakasai Y, Thang BQ, Kanemoto S, Takahashi-Igari M, Togashi S, Kato H, et al. Staged Repair of Pentalogy of Cantrell with Ectopia Cordis and Ventricular Septal Defect. J Card Surg. 2012;27:390-392.

10. Sepulveda W, Andreeva E, Machado LE. Sonographic diagnosis of ectopia cordis before 9 weeks of gestation. Prenat Diagn. 2014;34:1231-1232.

11. Chang Y, Yang MJ, Wang PH, Chen CY. Threedimensional HDlive image of ectopia cordis in a twin fetus at 9 gestational weeks. Taiwan J Obstet Gynecol. 2015;54:463-464.

12. Berry MJ, Saito-Benz M, Klein T, Bowkett B, Richardson V. Ectopia cordis: a novel palliative care technique. BMJ Support Palliat Care. 2016; doi: 10.1136/ bmjspcare-2015-000946. 